\title{
ПРОЯВЛЕНИЕ ПРИЗНАКОВ НЕОЛИТИЧЕСКОГО ПАКЕТА НА ТЕРРИТОРИИ ЛЕСНОЙ ПОЛОСЫ В VII - IV ТЫС. ДО Н.Э.
}

\section{(C) 2020 г. А.Ю. Назарова}

Статья посвящена анализу наиболее изученных культур неолита лесной полосы Прибалтики и Европейской части России (VII-IV тыс. до н.э.). Для анализа были отобраны следующие признаки неолитического пакета: керамика, шлифованные деревообрабатывающие орудия, долговременные жилища, крупные могильники, святилища и предметы импорта. В результате исследования были выделены наиболее развитые культуры раннего и среднего неолита, с учетом данных, которые существуют на сегодняшний день. В ранних культурах было обнаружено от 1 до 3 признаков, в среднем неолите было обнаружено от 3 до 5 заявленных признаков. В ходе работы, был прослежен процесс неолитизации лесной полосы.

Ключевые слова: археология, неолит, неолитический пакет, лесная полоса, керамика, шлифованные деревообрабатывающие орудия, долговременное жилище, могильник, святилище, взаимовыгодный обмен.

\section{MANIFESTATION OF NEOLITHIC PACKAGE SIGNS ON THE TERRITORY OF THE FOREST ZONE IN THE VII-IV THOUSAND BC}

\section{A.Yu. Nazarova}

The article is dedicated to an analysis of the most thoroughly studied Neolithic cultures of the forest zone of Eurasia $\left(7^{\text {th }}-4^{\text {th }}\right.$ millennia BC). The analysis involves the use of the following characteristics of the Neolithic package: ceramics, polished woodworking tools, long-term dwellings, large burial grounds, shrines, and items of non-local manufacture obtained in the course of economic exchange. As a result of the study, the most developed cultures of the early and middle Neolithic were identified, taking into account the information available today. In early cultures, a total of 1 to 3 features were discovered, and in the middle Neolithic - from 3 to 5. The process of neolithization of the forest zone was traced during the activities.

Keywords: archaeology, Neolithic, Neolithic package, forest zone, pottery, polished woodworking tools, long-term dwelling, burial ground, sanctuary, mutually beneficial exchange.

Целью нашего исследования является сравнительный анализ и выявление в неолитических культурах лесной полосы Евразии признаков, присущих неолитическому пакету. Хронологические рамки исследования с VII (VI) по IV (III) тыс. до н. э., так как именно этим временем датируются неолитические культуры лесной полосы Евразии. Территориальные рамки - от Восточной Прибалтики до Волго-Камья и Приуралья.

Неолитический пакет - это термин, используемый для определения материальной культуры разных народов (Юго-Западной Азии, Анатолии и Юго-Восточной Европы), в которой содержится скопление почти идентичных находок, встречающихся в разных географических зонах (Cilingiroglu, 2005).

Исследователи включают в неолитический пакет от 5 до 21 признака. После анализа ряда источников нами было выделено несколько универсальных признаков, которые присутствуют у многих исследователей в этой области в качестве ведущих. Мы определили следующий спектр: керамика, шлифованные каменные орудия для обработки дерева, долговременные жилища, святилища, могильники, а также предметы, которые могли попасть на территорию культуры вследствие экономического обмена (импорт).

Для советских и российских ученых керамика является основным признаком неолитизации и используется как маркер для определения неолитической эпохи. Следующим признаком является появление новых техник обработки каменных орудий. В частности техника шлифовки при создании рубящих орудий. Не менее важным составляющим является появление постоянных мест обитания - жилищ, как маркера оседлости населения. Одним из признаков является появление таких типов памятников, как святилища, в которых можно встретить наскальные изображения (писаницы и петроглифы). Такого рода памятники помогают не только познакомиться с искусством неолитической эпохи, но и увидеть, каким явлениям древний человек 
придавал наибольшее значение. Появление крупных могильников, находящихся за пределами поселений, также свидетельствует об усложнении общественных отношений. В эпоху неолита появляются зачатки экономического обмена между территориями, проявляющиеся в появлении «импортных» вещей или сырья. Все эти признаки свидетельствуют о том, на какой стадии неолитизации находилась та или иная культура.

Нами было проанализировано 10 археологических культур неолита: нарвская, сертейская, сперрингс, карельская, верхневолжская, льяловская, дубовская, балахнинская, волгокамская, камская. На некоторых территориях мы брали как культуры раннего неолита, так и более позднего времени. Это позволило нам проследить, как шел процесс неолитизации. Выбор культур был основан на том, что они достаточно хорошо изучены, и их данные можно использовать для сравнительного анализа.

В Восточной Прибалтике наиболее изученной является нарвская культура, которая расположена в восточной части современной Эстонии и относится к VI-IV тыс. до н. э. На памятниках данной культуры было обнаружено несколько видов глиняной посуды (горшки, блюдца, небольшие сосуды, удлиненные чаши) и шлифованные рубящие орудия. Основным материалом при изготовлении каменного инвентаря являлся кварц, так как в данном районе нет природных источников кремня. Кремень получали путем обмена с соседними территориями (Kriiska et al, 2017, p. 61-75). Это говорит о том, что уже на данном этапе появлялись зачатки взаимовыгодного обмена между близлежащими территориями, что указывает на высокий уровень развития культуры. В нарвской культуре изучены как сезонные постройки, так и долговременные жилища, углубленные в землю. Известно несколько поселений, в которых были обнаружены жилища круглой и овальной формы (Khrustaleva et al, 2020, p. 9-10). Крупным неолитическим могильником нарвской культуры является могильник Звейники (Stutz, Larsson, Zagorska, 201, p. 1019-1025). На территории нарвской культуры не было выявлено святилищ.

Исходя из представленной информации, мы видим, что в нарвской культуре имеются все признаки неолитического пакета, кроме святилищ.
В Днепро-Двинском междуречье располагается Сертейский археологический комплекс. В конце XX в. здесь была выделена сертейская ранненеолитическая культура VI - cep. V тыс. до н. э. Для данной культуры характерна керамика и кремневая каменная индустрия (Долбунова, 2015, с. 17-18). На памятниках культуры были найдены деревообрабатывающие шлифованные орудия (топоры, долотовидные орудия) (Долбунова, 2015, c. 80). Жилища представлены округлыми или овальными постройками. Они имеют небольшую площадь и углублены в землю не более чем на 0,2 м (Хрусталева, 2017, с. 144-146). Трудно назвать жилища такого типа долговременными. В данной ранненеолитической культуре не было обнаружено могильников вне поселений. Не было найдено информации о святилищах и импорте сырья для каменных орудий, так как здесь использовался местный кремень.

Таким образом, мы можем сказать, что в сертейской ранненеолитической культуре встречаются только два признака неолитического пакета: керамика и шлифованные деревообрабатывающие орудия.

На севере Восточной Европы, на территории Карелии и Ленинградской области, была выделена ранненеолитическая культура сперрингс (VI-V тыс. до н. э.) (Герман, 2018, с. 225-226). Для нее характерны как крупные, так и небольшие керамические сосуды. На памятниках были обнаружены шлифованные деревообрабатывающие инструменты (тесла, долота, стамески). Основным сырьем выступал сланец, из которого изготавливалось большинство орудий (Мельников, Герман, 2013, с. 26-30). Поселения культуры представлены кратковременными сезонными стоянками, без долговременных жилищ (Герман, Мельников, 2009 , с. 65). Одним из памятников культуры сперрингс является могильник Сандермоха, в котором вскрыто 107 неолитических погребений (Мельников, 1998, с. 14).

Таким образом, к ранненеолитической культуре сперрингс относится несколько признаков неолитического пакета: керамика, шлифованные деревообрабатывающие инструменты, крупные могильники.

Культуру сперрингс сменила карельская культура ямочно-гребенчатой керамики (кон. V - нач. III тыс. до н. э.). Как и на предыдущем этапе, здесь был обнаружен керамический комплекс (сосуды, миски, чаши) (Хорошун, 2011, с. 125-127). На территории 
культуры были найдены как сезонные стоянки, так и долговременные поселения площадью 1500-3000 м². (Археология Карелии, 1996, с. 84). В среднем площадь одного жилища составляла 40-50 м². Рядом с поселениями были обнаружены могильные комплексы, в которых было обнаружено около двух десятков могил, относящихся к неолиту (Археология Карелии, 1996, с. 89). Основным сырьем для создания орудий был кремень, сланец и кварц, которые добывались на данной территории. Для обработки дерева здесь использовались топоры, тесла, долота, стамески и т. д. Орудия были хорошо отшлифованы (Археология Карелии, 1996, с. 97-99).

На территории Онежского озера были найдены памятники, на которых расположены петроглифы, относящиеся к неолитической эпохе. Ранние изображения датируют V-IV тыс. до н. э., т. е они сопоставимы со временем существования карельской культуры. В комплексах изображены птицы, знаки, люди, животные и лодки. Подобные памятники говорят о высокой духовной культуре людей, которые их создали (Лобанова, 2016 , c. 12-16).

На памятниках, относящихся к карельской культуре, были обнаружены почти все признаки неолитического пакета. На данной территории не было выявлено предметов не местного производства. В погребальном инвентаре также не было найдено вещей, которые могли бы говорить об обмене. Мы можем сказать, что на данной территории процесс неолитизации был практически завершен.

Верхневолжская ранненеолитическая культура (VII-VI тыс. до н. э.) была выделена Д.А. Крайновым в 1973 г. (Цветкова, 2011, с. 157). Культура располагается на территории Верхнего Поволжья. К ней относят более 200 памятников. На всех этапах верхневолжской культуры был выделен основной признак неолитического пакета - керамика. Отличительной чертой стоянок является появление шлифованных рубящих орудий (Цветкова, 2011, с. 157-164). На территории верхневолжской ранненеолитической культуры не было обнаружено святилищ. По данной культуре не было найдено информации о долговременных жилищах и крупных могильниках. Так как верхневолжская культура относится к раннему неолиту, вполне вероятно, что эти признаки еще не сформировались.

Таким образом, мы видим, что на раннем этапе на территории центра Русской равни- ны существовали основные маркеры неолита: керамика и шлифованные рубящие орудия. В период существования верхневолжской культуры только начинался процесс неолитизации региона.

На смену верхневолжской культуре приходит льяловская. Время существования льяловской культуры относится к рубежу VI-V тыс. до н. э. - до IV тыс. до н. э. (Карманов, 2012, c. 424-426). Как и на более раннем этапе здесь присутствует керамическая посуда. Льяловской культуре присущи шлифованные рубящие орудия из некремневых пород (песчаник, алевролит, сланец). Для культуры характерны долговременные жилища, представленные полуземлянками от 21 до 100 м² (Карманов, 2008, с. 66-70). К данной культуре относят 15 погребений на могильнике Сахтыш IIa (Костылева, 2018, с. 291). В погребениях было найдено несколько янтарных украшений. Это говорит о том, что уже на этом этапе здесь появлялся экономический обмен с соседними территориями (Костылева, Уткин, 2010, с. 218). На памятниках льяловской культуры не было обнаружено святилищ.

Таким образом, здесь было обнаружено 5 признаков: керамика, шлифованные деревообрабатывающие орудия, долговременные жилища, могильник и импорт. Так как основные признаки неолитического пакета присущи данной культуре, можно сказать, что она обладала достаточно высоким уровнем развития.

Ранненеолитическая культура Марийского Поволжья была выделена во время исследования мезолитических стоянок Халиковым А.Х. в 50-е г. ХХ в. Исходя из исследований последних лет, этот период в Марийском Поволжье назван дубовской ранненеолитической культурой (рубеж VII-VI тыс. до н. э.). Начальные этапы культуры относятся к "докерамическому неолиту". Исследователи основывают свои выводы на том, что уже на этом этапе здесь были выявлены крупные поселения с долговременными постройками. На территории культуры найдены постройки, углубленные от 0,3 м до 1,0 м и площадью до $87 \mathrm{M}^{2}$. Позже здесь появляется керамика. Большая часть сосудов данного периода не имеет орнамента (Никитин, 2017, с. 171-175). Каменные орудия во многом повторяют комплекс предшествующего периода. На данном этапе рубящие орудия практически не обрабатывались в технике шлифовки. Здесь был найден лишь 
один шлифованный топор (Никитин, 2019, с. 70-71).

Таким образом, мы видим, что на раннем этапе основным признаком неолитизации является появление долговременных жилищ, что означало, что население Марийского Поволжья перешло к оседлости. Главный маркер неолита - керамика, появляется на данной территории на более позднем этапе.

Дубовскую культуру в Марийском Поволжье сменяет балахнинская культура с гребенчато-ямочной керамикой (VI-IV тыс. до н. э.). Исследование памятников ведется с середины прошлого столетия. Главный маркер неолитического пакета - керамика, был выявлен в данной культуре. К балахнинской культуре относится несколько долговременных жилищ. Они представляли собой полуземлянки площадью до 70 м². В каменной индустрии в основном использовались кремень, песчаниковые породы и кварцит (Никитин, 2017, с. 171-175). Здесь были обнаружены тщательно отшлифованные деревообрабатывающие орудия (Никитин, 2019, с. 70-71). На данных памятниках не было изучено крупных могильников, святилищ и предметов не местного производства.

Исходя из этого, мы видим, что к балахнинской культуре относится 3 маркера неолитического пакета: керамика, шлифованные деревообрабатывающие орудия и долговременные жилища.

В Прикамье (бассейн Камы в пределах Пермского края, Кировской области, Удмуртии, севера Башкирии, востока Татарстана) была выделена волго-камская ранненеолитическая культура (VII - вторая половина VI тыс. до н. э.) (Лычагина, 2019, с. 268). К данной культуре принадлежат небольшие керамические сосуды с плоским дном, а также шлифованные рубящие орудия (Гусенцова, 1993, с. 81-83). Известны жилища подквадратной и подпрямоугольной формы, углубленные в материк на 0,15-0,40 м (Лычагина, Цыгвинцева, 2013, с. 22). В волго-камской культуре не было выявлено крупных могильников, святилищ и предметов не местного производства.

Таким образом, в волго-камской ранненеолитической культуре были выделены 3 признака неолитического пакета: керамика, шлифованные рубящие орудия и долговременные жилища.

В середине прошлого века О.Н. Бадером была выделена камская неолитическая культура (VI-IV тыс. до н. э.). Для культуры характерны крупные сосуды полуяйцевидной формы. На памятниках камской культуры были обнаружены шлифованные деревообрабатывающие орудия (долота и тесла). Каменные изделия создавались из кремневого известняка и из кремня местных пород (Габяшев, 2003, с. 17-40). Жилища представлены как слабоуглубленными полуземлянками, так и землянками. Внутри были обнаружены очаги и ниши для хранения запасов (Лычагина, 2019, с. 227-238). В камской культуре не было найдено погребальных комплексов.

На территории камской культуры были выделены такие памятники, как святилища, в которых были найдены наскальные рисунки - писаницы. К неолиту относят изображения лосей, антропоморфных существ на Камне Писаном на р. Вишера (Лычагина, 2019, с. 33).

Подводя итог по камской неолитической культуре, мы можем сказать, что здесь было обнаружено 4 признака неолитического пакета: керамика, шлифованные деревообрабатывающие орудия, долговременные жилища и святилища.

Исходя из анализа культур лесной полосы, мы можем сказать, что они имеют разный состав неолитического пакета. Наиболее часто встречаются такие признаки, как керамика и шлифованные деревообрабатывающие орудия, которые были выделены практически во всех культурах. Реже мы видим поселения, в которых встречаются крупные жилища, служившие постоянным местом обитания и маркером оседлости. Самыми редкими из признаков оказались святилища, предметы не местного производства и крупные могильники.

Среди ранненеолитических культур, исходя из использованного набора признаков, наиболее продвинутыми выглядят культура сперрингс и волго-камская, так как в них было обнаружено 3 признака неолитического пакета: керамика, шлифованные рубящие орудия, крупный могильник (сперригс) и долговременные жилища (волго-камская). Меньше всего признаков среди ранненеолитических культур было выявлено в дубовской культуре, которая изначально была отнесена к "докерамическому неолиту" и лишь на позднем ее этапе было выделено 2 признака (долговременные жилища и керамика).

Среди культур среднего неолита по пять заявленных признаков было выделено в льяловской и карельской культурах Мы полагаем, что в рамках этих культур процесс 
неолитизации в лесной полосе практически завершился. Менее развитой выглядит балахнинская культура Марийского Поволжья, так как там было обнаружено 3 признака неолитического пакета (керамика, шлифованные орудия и долговременные жилища). Возможно, это связано с уровнем изученности данной культуры.

После анализа культур раннего и среднего неолита, мы можем видеть, как на разных территориях протекал процесс неолитизации. На территории центра Русской равнины после перехода от ранненеолитической культуры к среднему неолиту к основным признакам (керамике и шлифованным рубящим орудиям) добавляются долговременные жилища, крупные могильники и появляется взаимовыгодный обмен.

\section{ЛИТЕРАТУРА}

Археология Карелии / Отв. ред. М.Г. Косменко, С.И. Кочкуркина. Петрозаводск: КарНЦ РАН, 1996. $416 \mathrm{c}$.

Габямев Р.С. Население Нижнего Прикамья в V-III тысячелетиях до нашей эры. Казань: Ин-т истории им. Ш. Марджани АН РТ, 2003. 226 с.

Герман К.Э. Культура сперрингс (современное состояние изучения) // Самарский научный вестник. T. 7. № 3 (24). 2018. C. 225-230.

Герман К.Э., Мельников И.В. Поселения мезолита - раннего неолита Южного Заонежья (Республика Карелия) // Мезолит и неолит Восточной Европы: хронология и культурное взаимодействие. / Отв. ред. С.А. Васильев, В.Я. Шумкин. СПб.: ИИМК РАН, МАЭ РАН, 2012. С. 57-68.

Гусенцова T.M. Мезолит и неолит Камско-Вятского междуречья. Ижевск: Изд-во Удмурт. ун-та, 1993. $237 \mathrm{c}$.

Долбунова Е.В. Древнейшие керамические традиции в Днепро-Двинском Междуречье (7-6-го тыс. до н. э.). Дисс... канд. ист. наук. Санкт-Петербург, 2015. 380 с.

Карманов В.Н. Неолит европейского Северо-Востока. Сыктывкар, 2008. 226 с.

Карманов В.Н. Неолитическое население на европейском Северо-Востоке: обитание или пребывание? // Первобытные древности Евразии / Отв. ред. С.В. Ошибкина. М.: ИА РАН, 2012. С. 419-446.

Костылева Е.Л. Артефакты из органических материалов из захоронений и «святилищ» могильника Сахтыш ІІа (Центральная Россия) // Historia provinciae - журнал региональной истории. 2018. №4. C. 286-325.

Костылёва Е.Л., Уткин А.В. Нео-энеолитические могильники Верхнего Поволжья и Волго-Окского междуречья: планиграфические и хронологические структуры. М.: ТАУС, 2010. 300 с.

Лобанова Н.В. Новые данные о периодизации наскального искусства Онежского озера // Альманах североевропейских и балтийских исследований. 2016. № 1. С. 12-34.

Лычагина Е.Л. Неолит Верхнего и Среднего Прикамья. Дисс... д-ра. ист. наук. Пермь, 2019. 632 с.

Лычагина Е.Л., Цыгвинщева Т.А. Сравнительный анализ ранненеолитических культур Прикамья // Вестник Пермского университета. Серия История. 2013. №1 (21). С. 22-36.

Мельников И.В. Святилища древней Карелии: (Палеоэтногр. очерки о культовых памятниках). Гос. ист.-архитектур. и этногр. музей-заповедник "Кижи". 1998. 133 с.

Мельников И.В., Герман К.Э. Древние поселения южного Заонежья (мезолит - энеолит). Петрозаводск: ФГБУК «Государственный историко-архитектурный и этнографический музей-заповедник “Кижи"», 2013. 409 с.

Никитин В.В. Итоги изучения каменного века в Марийском Поволжье // Поволжская археология. 2017. №3 (21). C. 168-189. 
Никитин В.B. Мезолит и неолит Марийского Полесья (эволюция, проблемы выделения культур) // Эволюция неолитических культур Восточной Европы (Санкт-Петербург, 15-17 мая, 2019) / Отв. ред. А.А. Выборнов, Е.В. Долбунова, Е.М. Колпаков, Е.С. Ткач. СПб.: ООО «Порто-Принт», 2019. С. 69-71.

Хорошун T.A. К вопросу смены культур в неолите раннем энеолите Карелии (по материалам памятников западного побережья Онежского озера) // Труды Карельского научного центра Российской академии наук. 2011. №6. С. 124-132.

Хрусталева И.Ю. Постройки позднего этапа заселения памятника Сертея XIV: культурная атрибуция и возможности графической реконструкции // Самарский научный вестник. 2017. №3(20). C. $143-150$.

Цветкова Н.А. Ранний неолит Верхнего Поволжья: некоторые итоги изучения // Российский археологический ежегодник. № 1. / Глав. ред. Л.Б. Вишняцкий. СПб.: Изд-во С.-Петерб. ун-та, 2011. C. $148-182$.

Cilingiroglu, $C$. The concept of «Neolithic package»: considering its meaning and applicability // Documenta Praehistorica. 2005. Vol. XXXII. P. 1-13.

Khrustaleva I., Roog R., Kholkina M., Kriiska A. Hunter-gatherer pit-houses in Stone Age Estonia // Archaeological and Anthropological Sciences. 2020. 12(2). 56. P. 1-17.

Kriiska A., Oras E., Lõugas L., Meadows J., Lucquinand A., Craig O.E. Late Mesolithic Narva Stage in Estonia: pottery, settlement types and chronology // Estonian Journal of Archaeology. 2017. №1 (21). P. 52-86.

Stutz L., Larsson L., Zagorska I. The persistent presence of the dead: Recent excavations at the huntergatherer cemetery at Zvejnieki (Latvia) // Antiquity. 2015. 87 (338) P. 1016-1029.

\section{Информация об авторе:}

Назарова Анастасия Юрьевна, Пермский государственный гуманитарно-педагогический университет (г. Пермь, Россия); nnazarowa@mail.ru

\section{REFERENCES}

Kosmenko, M. G., Kochkurina, S. I. (eds.). 1996. Arkheologiia Karelii (Archaeology of the Karelia). Petrozavodsk: Karelian Research Center RAS Publ., (in Russian).

Gabiashev, R. S. 2003. Naselenie Nizhnego Prikam'ia v V-III tysiacheletiiakh do n.e. (Population of the Lower Kama during the V-III Millennia BC). Kazan: Institute of History named after Sh. Mardzani, Tatarstan Academy of Sciences; "Fän" Publ. (in Russian).

German, K. E. 2018. In Samarskii nauchnyi vestnik (Samara Scientific Bulletin) 24 (3), 8-27 (in Russian).

German, K. E., Mel'nikov, I. V. 2012 In Vasil'ev, S. A., Shumkin, V. Ya. (eds.) Mezolit i neolit Vostochnoi Evropy: khronologiia i kul'turnoe vzaimodeistvie (Mesolithic And Neolithicof Eastern Europe: Chronology And Culture Interaction). Saint Petersburg: Institute for the History of Material Culture, Russian Academy of Sciences, Peter the Great Museum of Anthropology and Ethnography (Kunstkamera) of Russian Academy of Sciences, 57-68 (in Russian).

Gusentsova, T. M. 1993. Mezolit i neolit Kamsko-Viatskogo mezhdurech'ia (Mesolithic and Neolithic of the Kama-Viatka Interfluve). Izhevsk: Udmurt University (in Russian).

Dolbunova, E. V. 2015. Drevneishie keramicheskie traditsii v Dnepro-Dvinskom mezhdurech'e (7-6-go tys. do n.e.) (The Earliest Ceramic Traditions in the Dnieper and Dvina Interflivial Zone in 7th - 6th Millennia $B C$ ). PhD Diss. Saint Petersburg (in Russian).

Karmanov, V. N. 2008. Neolit evropeiskogo Severo-Vostoka (Neolithic of European Notheast). Syktyvkar (in Russian).

Karmanov, V. N. 2012. In Oshibkina, S. V. (ed.). Pervobytnye drevnosti Evrazii (Prehistoric objects from Eurasia). Moscow: Institute of Archaeology, Russian Academy of Sciences, 467-498 (in Russian).

Kostyleva, E. L. 2018. In Historia provinciae - zhurnal regionalnoi istorii (Historia Provinciae - the Journal of Regional History). 4, 286-325 (in Russian).

Kostyleva, E. L., Utkin, A. V. 2010. Neo-eneoliticheskie mogil'niki Verkhnego Povolzh'ya i Volgo-Okskogo mezhdurech'ya: planigraficheskie i khronologicheskie struktury (Neolithic -Eneolithic Burial Grounds on the Upper Volga and the Volga-Oka Interfluve: Planigraphic and Chronological Structures). Moscow: "TAUS" Publ. (in Russian).

Lobanova, N. V. 2016. In Al'manah severoevropejskih i baltijskih issledovanij (Almanac of North European and Baltic Studies) 1. 12-34 (in Russian). 
Lychagina, E. L. 2019 Neolit Verkhnego i Srednego Prikam'ia (Neolithic of the Upper and Middle Kama Regions) Diss. of doctor of historical Sciences. Perm (in Russian).

Lychagina, E. L., Tsygvintseva, T. A. 2013. In Vestnik Permskogo universiteta. Seriia «Istoriia» (Bulletin of the Perm University. History Series) 21 (1), 22-36 (in Russian).

Mel'nikov, I. N. 1998. Svjatilishha drevnej Karelii: (Paleojetnogr. ocherki o kul'tovykh pamjatnikakh). (Sanctuaries of Ancient Karelia (Paleoethnic Essays on Cult Monuments)). Petrozavodsk: Kizhi MuseumReserve (in Russian).

Mel'nikov, I. V., German, K. E. 2013. Drevnie poseleniia yuzhnogo Zaonezh'ia (mezolit - eneolit). (Ancient Settlements of Southern Trans-Onega Region (Mesolithic - Eneolithic). Petrozavodsk: Kizhi MuseumReserve (in Russian).

Nikitin, V. V. 2017. In Povolzhskaya arkheologiya (Volga River Region Archaeology) 21 (3), 184-196 (in Russian).

Nikitin, V. V. 2019. In Vybornov, A. A., Dolbunova, E. V., Kolpakov, E. M., Tkach, E. S. (eds.). Evolyutsiia neoliticheskikh kul'tur Vostochnoi Evropy (Evolution of the Neolithic Cultures of Eastern Europe (Saint Petersburg, 15-17. 05. 2019). Saint Petersburg: "Pronto-Print"Publ., 69-71 (in Russian).

Khoroshun, T. A. 2011. In Trudy Karel'skogo nauchnogo centra Rossiiskoi akademii nauk (Proceedings of the Karelian Scientific Center of the Russian Academy of Sciences) 20 (3), 124-132 (in Russian).

Khrustaleva, I. Yu. 2017. In Samarskii nauchnyi vestnik (Samara Scientific Bulletin) 20 (3), 143-150 (in Russian).

Tsvetkova, N. A. 2011. In Vishnyatsky, L. B. (ed.). Rossiiskii arkheologicheskii ezhegodnik (Russian Archaeological Yearbook) 1. Saint Petersburg: Saint Petersburg University, 148-182 (in Russian).

Cilingiroglu, C. 2005. In Documenta Praehistorica. Vol. XXXII, 1-13.

Khrustaleva, I., Roog, R., Kholkina, M., Kriiska, A. 2020. In Archaeological and Anthropological Sciences. 12(2). 56, 1-17.

Kriiska, A., Oras, E., Lõugas, L., Meadows, J., Lucquinand, A., Craig, O. E. 2017. In Estonian Journal of Archaeology. 1 (21), 52-86.

Stutz L., Larsson L., Zagorska I. 2015. In Antiquity. 87 (338), 1016-1029.

\section{About the Author:}

Nazarova Anastasia Yu. Perm State Humanitarian Pedagogical University (PSHPU).Sibirskaya Str., 24, Perm, 614990, Russian Federation; nnazarowa@mail.ru

Статья поступила в журнал 01.08.2020 г.

Статья принята к публикации 01.09.2020 г. Авторы внесли равноценный вклад в работу. 